\title{
The Comparison of Selected Physical and Physiological Parameters of Elite Basketball Players According to their Playing Positions
}

\author{
ALI EMRE EROL ${ }^{1}$, ŞEYDA ÇELIK KARAHANÇER ${ }^{1}$, SEMA ÖZDEN ${ }^{1}$, HÜRMÜZ KOÇ ${ }^{2}$ \\ ${ }^{1}$ Cyprus International University, School of Physical Education and Sports, KKTC \\ ${ }^{2}$ Çanakkale Onsekiz Mart University, Faculty of Sports Sciences, TC
}

\begin{abstract}
Background: This research was conducted to compare the physical and physiological parameters of elite basketball players according to their playing positions and to contribute to the literature.

Methods: Eighteen elite basketball players who regularly train and compete in the national team participated in the research voluntarily. Participants were grouped as guard, forward and center according to the pitch positions. Vertical jump and sprint tests were used to evaluate the anaerobic performance of the participants. The Yo-Yo intermittent recovery test was applied to evaluate the aerobic performances. In addition, hemogram analyzes of the blood samples of the participants were made and hematocrit and hemoglobin parameters related to aerobic performance were examined. Kruskal Wallis-H and Mann Whitney $U$ tests were used for statistical analyses.

Results: The analyzes show that the guards had higher vertical jump, yo-yo and VO2max averages compared to the centers, and a significantly lower $30 \mathrm{~m}$ running average. It was determined that the forward players had higher anaerobic power than the guards, and yo-yo running and VO2max averages were significantly higher than the center players.

Conclusion: In conclusion, it is thought that the difference between guard, forward and center players who voluntarily participated in the study is due to the physical characteristics of the basketball players and the different training programs applied to the players playing in different positions.
\end{abstract}

Keywords: Basketball Player, Playing Position, Physical Characteristics, Physiological Characteristics

\section{INTRODUCTION}

While creating a research in the world of science, it is aimed to reveal a scientific fact with different methods by applying a known method to a new domain or a new method to a new domain. Quantitative and qualitative studies come to the fore in this regard. This research is a normative study that uses quantitative research method to analyze the numerical values of physical and physiological measurements.

Basketball, which has thousands of players and millions of spectators in the world and in our country, has become a part of life as one of the most important sports branches. The most important goal in the world of sports is to achieve success. The aim of all athletes is to win the competition in which they participate. In order to achieve this goal, the elements that make up the sportive performance of the athletes ${ }^{3,16}$ should increased to a higher level.

Basketball is a team game where some players can play in more than one position due to its structure ${ }^{34}$. In basketball, it is important for the players playing in each position to show high performance in order to win the match. Studies show that the most important factor over victory is the accurate shooting $11,14,21$.

In basketball, the positions of the players in the game are expressed according to their positions on the field. Generally, basketball teams have three main positions: forward, guard, and center. Considering the basketball game structure, the guards do not need to be very tall because they are playmakers. As for forward and center players, it is natural that they are preferred over taller players, as they engage in under the crucible or rebound fights a lot ${ }^{18}$. The main purpose of basketball players playing in different zones and portions is to score points and win with accurate shots on the basket ${ }^{25}$. From this point of view, the most important factor in establishing superiority in basketball competition and winning the game is the skill and the percentage of shooting ${ }^{21}$. For this reason, the first step towards increasing the quality of training time in the basketball is the intense application of shooting techniques from different zones, with the method in which the athlete is most successful ${ }^{10}$.

Considering the duration of the matches and the necessity of playing quickly and accurately in basketball, it is known that basic motoric features such as strength, speed, endurance, mobility and coordination are important for both defense and offense, as well as tactics for the players In addition to these features, it is a fact that compound motoric features such as quick strength and continuity in strength are required. Other variables that complement these characteristics in success are the aerobic and anaerobic capacity of the athletes 28, 9, 30. Considering that basketball is a game played very quickly over four periods in front of a large spectators on a small court, it is a fact that basketball players must be at the highest level in terms of aerobic and anaerobic power.

In the literature, it was concluded that anaerobic power parameters are important factors for basketball performance ${ }^{26}$. Although studies on basketball players generally emphasize anaerobic capacity, it is very difficult to consider anaerobic and aerobic systems independently of each other during training.

These elements, which are independent as physiological systems, are interrelated during activity. Aerobic power is the amount of oxygen that a person can use per unit time, and the higher it is, the higher the aerobic capacity of the person. The quality and level of long-term exercises are closely related to VO2max. Aerobic power is the most important factor affecting performance in endurance sports. There is a high dependence between maximal aerobic capacity and the ability to sustain a 
vigorous effort $29,13,31$. It is known that aerobic capacity is an effective variable, considering the ability to withstand long training sessions and matches lasting over 40 minutes in basketball. Gaming performance is affected by both aerobic and anaerobic metabolism ${ }^{2}$.

From this point of view, this study was conducted with the aim of comparing the physical and physiological parameters of elite basketball players selected according to their pitch positions.

\section{MATERIAL \& METHODS}

Eighteen elite basketball players who train regularly and participate in competitions in the national team voluntarily participated in the research. Participants were grouped as guard $(n=9)$, forward $(n=4)$ and center $(n=5)$.

Demographic information: Information forms prepared by the researchers were applied to the participants in order to determine the general characteristics of the participants.

Anthropometric Measurements: The height measurements of the participants were measured using a Seca brand staiometer and recorded in $\mathrm{cm}$. Body weight measurements of the participants were made using Tanita brand bioelectrical impedance devices and recorded in $\mathrm{kg}$.

Anaerobic Performance Tests: In order to determine the anaerobic performance of the participants, $30 \mathrm{~m}$ sprint and vertical jump tests were applied.

30m Sprint Test: After a standard warm-up period lasting 5-10 minutes, the test was carried out on the $30 \mathrm{~m}$ test track determined in the indoor gym, where the start and end points were determined by photocells. When the participants felt ready to stop at the starting point, they were asked to run to the finish point with maximum effort. During the run, the participants were given verbal support. The test was administered to each participant twice, and the lowest time in seconds was considered the test score.

Vertical Jump Test: The vertical jump performances of the participants were tested using the Takei digital jump meter (5414 jump-DF, Takei, Japan). The test was performed with a standard warm-up period lasting 5-10 min. Participants were asked to stand in the center of the elastic mat on which they would jump. In order to determine the jump height of the participants, the belt of the device was tied to the abdomen. Participants were asked to jump as high as possible, allowing them to bend their knees and swing their arms without taking a step. The test was applied twice and the highest value in $\mathrm{cm}$ was accepted as the test score and recorded. According to the test score, the anaerobic power values of the participants were calculated using the Lewis formula. $P(\mathrm{~kg} / \mathrm{m} / \mathrm{sec}-1)=\sqrt{ } 4.9 \times$ Body Mass $(\mathrm{kg}) \times \sqrt{ }$ Jumpreach score $(\mathrm{m})$.

Hemogram Analysis: Blood samples were taken from the antecubital region of the forearm by two nurses at 9:00 am following an eight-hour fast, in accordance with the hygiene rules, and blood samples with $5 \mathrm{ml}$ of EDTA (ethylene diaminetetra-acetic acid) were taken. Blood hematological levels were analyzed using Architect brand blood counting device. The hematocrit and hemoglobin values obtained from the analysis results were used in statistical analysis.

Aerobic Performance Test: In order to determine the aerobic performance of the participants, the YoYo Intermittent Recovery Running Test was performed.

Yo-Yo Intermittent Recovery Running Test: The test was carried out in the indoor sports hall, on the track consisting of $20 \mathrm{~m}$ running and $5 \mathrm{~m}$ running areas, the boundaries of which were determined by lines and funnels. Participants were asked to warm up individually for 10-15 minutes before the test. After the warm-up period, the participants were invited to the test track. After the attention was given about the audio warning system that determines the track and running pace, the test was started at $10 \mathrm{~km} / \mathrm{h}$. During the test, the number of sit-ups of the participants were recorded on the standard running tracking form. The test was terminated when the participant stopped running or could not complete the $40 \mathrm{~m}$ lap twice in accordance with the audible warning, and the valid number of shuttles was recorded as the test result. According to the test result, Bangsbo et al. (2008), the VO2max values of the participants were calculated using the estimation formula ${ }^{5}$. Data Analysis: The Kruskal Wallis- $\mathrm{H}$ test was used in multiple comparisons, since the performance data of the participants grouped as guard, forward and center in the study showed nonparametric distribution according to the Shapiro Wilk test results. The Mann Whitney $U$ test was used to determine the source of the difference in the parameters that were found to be significantly different as a result of this test. Significance level was accepted as $\mathrm{p}<0.05$.

\section{RESULTS}

Descriptive information about the participants is given in Table 1. The statistical comparisons of performance tests, aerobic-anaerobic capacities and blood values of the participants according to the positions they played in basketball competitions are presented in Table 2. When comparing the performance parameters of the participants according to pitch positions, it was determined that there were statistically significant differences between the groups in the averages of vertical jump, $30 \mathrm{~m}$ running, anaerobic power, Yo-Yo running and VO2max ( $p>0.05)$. According to the vertical jump test results we found that the average score of the guards was significantly higher than the forwards ( $z=-2547, p=0.007)$. According to the results of the $30 \mathrm{~m}$ running test, it was determined that the mean score of the guards was significantly lower than the centers $(z=-2539, p=0.007)$. According to the anaerobic power values, the mean score of the guards was found to be significantly lower than the forwards $(z=-3003, p=0.001)$. According to Yo-Yo running test and VO2max results, it was determined that the mean score of the centers was significantly lower than both the guards $(z=-3003, p=$ $0.001)$ and the forwards $(z=-2449, p=0.014)$. There was no statistically significant difference between the groups according to the hemoglobin and hematocrit averages of the participants $(p>0.05)$. 
Table 1. Descriptive characteristics of the participants

\begin{tabular}{|l|l|l|l|l|l|}
\hline Variables & Group & & $\begin{array}{l}\text { Forward } \\
\text { (n= 4) }\end{array}$ & $\begin{array}{l}\text { Center } \\
\text { (n= 12) }\end{array}$ \\
\cline { 2 - 5 } & $\begin{array}{l}\text { Guard } \\
\text { (n= 9) }\end{array}$ & & $\mathbf{X}(\mathbf{S S})$ & $\mathbf{X}(\mathbf{S S})$ \\
\cline { 2 - 5 } & $\mathbf{X}$ (SS) & $25.0(1.63)$ & $30.60(3.84)$ \\
\hline Age (Years) & $26.56(2.83)$ & $202(4.62)$ & $207.6(3.65)$ \\
\hline Height (cm) & $191.11(4.04)$ & $99.0(2.0)$ & $106.0(6.52)$ \\
\hline Weight (kg) & $86.11(7.32)$ & $9.0(2.82)$ & $17.0(3.31)$. \\
\hline Traning Age (Year) & $13.11(6.68)$ & & \\
\hline
\end{tabular}

Table 2. Analysis of the performance parameters of the participants according to their pitch positions

\begin{tabular}{|c|c|c|c|c|c|}
\hline \multirow[t]{3}{*}{ Parameter } & \multicolumn{3}{|l|}{ Group } & \multirow[t]{3}{*}{$\mathbf{p}$} & \multirow{3}{*}{ Difference } \\
\hline & $\begin{array}{l}\text { Guard (G) } \\
(n=9)\end{array}$ & $\begin{array}{l}\text { Forward (F) } \\
(n=4)\end{array}$ & $\begin{array}{l}\text { Center }(C) \\
(n=12)\end{array}$ & & \\
\hline & X (SS) & X (SS) & X (SS) & & \\
\hline Veritcal Jump (cm) & $65.67(4.5)$ & $70.25(13.79)$ & $58.20(2.95)$ & $0.045^{\star}$ & $\mathrm{G}>\mathrm{P}$ \\
\hline Anaerobic Power (W) & $166.64(11.15)$ & $187.43(10.41)$ & $171.38(11.27)$ & $0.030^{*}$ & $\mathrm{G}<\mathrm{F}$ \\
\hline 30 m Run(s) & $3.37(0.28)$ & $3.56(0.36)$ & $3.96(0.20)$ & $0.017^{*}$ & $\mathrm{G}<\mathrm{P}$ \\
\hline $\begin{array}{l}\text { Yo-Yo Running } \\
\text { (number) }\end{array}$ & $73.78(3.34)$ & $74.75(5.31)$ & $60.80(5.21)$ & $0.006^{*}$ & $\begin{array}{l}\mathrm{G}>\mathrm{P} \\
\mathrm{F}>\mathrm{P}\end{array}$ \\
\hline VO2max (ml/kg/min) & $52.33(2.76)$ & $49.55(1.10)$ & 43.62 (2.54). & $0.003^{*}$ & $\begin{array}{l}G>P \\
F>P\end{array}$ \\
\hline Hemoglobin (g/dl) & $132.93(3.92)$ & $133.87(10.4)$ & $131.48(4.51)$ & 0.585 & - \\
\hline Hematocrit (\%) & $43.6(1.81)$ & $41.5(1.0)$ & $42.0(1.58)$ & 0.111 & - \\
\hline
\end{tabular}

${ }^{*} \mathrm{p}<0.05$

\section{DISCUSSION}

It is a very important parameter for the athlete to fulfill his role in the team in athletic success. While the athlete achieves success only according to his own performance in individual sports, the performance of all athletes forming the team gains importance in team sports. From this point of view, the evaluation of the performance of the athletes in the team according to the position they play is an important finding for scientific research.

In basketball, it is necessary that the basic motoric features such as strength, speed, endurance, mobility and coordination, especially aerobic and anaerobic capacities, should be exhibited at a high level.

The concept of basketball requires many skills such as jumping, running and changing direction. Anaerobic power is used more than aerobic power and $15 \%$ of the game is at high intensity ${ }^{23}$. Basketball is a team game where some players can play in more than one position due to its structure ${ }^{34}$. In order to win the game, players must have the ability to shoot accurately. Studies show that the most important factor in winning the game and establishing superiority is the ability to shoot accurately ${ }^{11}$, 14,21 .

Our main argument in this study is that physical and physiological parameters are effective at the performance level of the elite basketball players. The players must have certain characteristics and among them height is the most important and the main parameter affecting the success. Height was $191.11 \pm 4.04 \mathrm{~cm}$ for guards, $202.0 \pm 4.62 \mathrm{~cm}$ for forwards, and $207.6 \pm 3.65 \mathrm{~cm}$ for pivots (Table 1 ). When we look at the studies conducted in this domain, we determined that the basketball players who participated in our study had a higher average height in 7, 8, 4, 17 .

Studies in the literature ${ }^{1}$ compare the zone 1 players to toher zones in terms of body fat ratio and aerobic power performance. As a result zone 1 players are found to have lower body fat ratio and higher aerobic performance.
Similar results were given in ${ }^{18}$, where guard players have lower body fat ratio and there is a significant difference in terms of aerobic capacity of the players.

Vertical jump was $65.67 \pm 4.5 \mathrm{~cm}$ on the guards, $70.25 \pm 13.79 \mathrm{~cm}$ on the forwards and $58.20 \pm 2.95 \mathrm{~cm}$ on the centers. Anaerobic power calculated from the vertical jump was $166.64 \pm 11.15 \mathrm{~kg}$ on the guards. $\mathrm{m} / \mathrm{sec}$ was determined as $187.43 \pm 10.41 \mathrm{~kg} \cdot \mathrm{m} / \mathrm{sec}$ in the forwards and $171.38 \pm 11.27 \mathrm{~kg} . \mathrm{m} / \mathrm{sec}$ in the center.

A study on elite players found that forwards and guards showed better jumping characteristics than centers 19. Vertical jumping is a skill that includes a complex array of moves. Success especially depends on lower extremity muscle strength and jumping technique. Therefore, determining the strength of the lower extremities and preparing the training programs of the athletes in is important to increase the performance 20; 27; 15. Menevşe (2013) found that there was no statistical significance between forwards and guards in terms of vertical jump and anaerobic power variables, a significant difference was found between centers and the other two positions (forward and guard) ${ }^{22}$.

The fact that the guard players have lower anaerobic power values compared to the players in other positions is due to the different training programs applied and individual characteristics of these players. When the literature is examined, the mid-level anaerobic power values of male athletes between the ages of 20-30 are $140-175 \mathrm{kgm} / \mathrm{sec}$.; good level values are stated as $176-210 \mathrm{kgm} / \mathrm{sec} .{ }^{12}$. In this study, the values obtained for anaerobic power are in parallel with the average values of Fox.

Considering the game characteristics of basketball, agility is thought to be an important motoric feature in determining performance. Acceleration, deceleration, and direction changing skills, which are indicators of agility, are heavily involved in basketball ${ }^{35}$.

In the our study, we determined that the average score of the vertical jump for guards was significantly 
higher than the forwards. According to the results of the 30 $\mathrm{m}$ running test, we see that the average score of the guards was significantly lower than the centers. According to the anaerobic power values, the average score of the guards was found to be significantly lower than the forwards. Yo-Yo running test and VO2max results showed that centers had lower scores than both guards and forwards. There was no statistically significant difference between the groups according to the hemoglobin and hematocrit averages of the participants.

High VO2max values are thought to be associated with more intense exercise or competition, and therefore, it is recommended to improve the aerobic capacity of basketball players both in-season and inter-season recovery and to maintain their performance 24, 6, 32. High VO2max values also improve the ability of players to recover after anaerobic efforts during the competition ${ }^{33}$.

\section{CONCLUSION}

As a result, when players in different pitch positions are compared, statistically significant differences are found between the groups in the averages of vertical jump, $30 \mathrm{~m}$ running, anaerobic power, Yo-Yo running and VO2max. Considering the game structure of basketball, the guards do not need to be very tall because they are playmakers. Forward and center players, on the other hand, are naturally preferred among longer players, as they engage in under the crucibleor rebound fights a lot. The first duty of the guards is playmaker. It is a normal result that spattering or other technical characteristics do not improve ${ }^{18}$.

As a result, it is thought that the difference between guard, forward and center players who voluntarily participated in the study is due to the physical characteristics of the basketball players and the different training programs applied to the players playing in different positions. The repetition of such studies by increasing the number of participants will make a serious contribution to the literature in terms of forming a consensus on this issue.

\section{REFERENCES}

1. Abdelkrim, N. B., El Fazaa, S., \& El Ati, J. Time-motion analysis and physiological data of elite under-19-year-old basketball players during competition. British Journal of Sports Medicine, 2007; 41(2), 69-75.

2. Araujo, G. G., Manchado - Gobatto, F. B., Papoti, M., Camargo, B. H. F., and Gobatto, C. A. Anaerobic and aerobic performances in elite basketball players. Journal of Human Kinetics, 2013; 42(1), 137-147.

3. Astrand, P. O;Rodahl, K: Textbook of Work Physiology. Mc Graw H ill Book Company. 3. Edition. pp1-5 1986.

4. Bale, P., Scholes, S., Lateral dominance and basketball performance. Journal of Human Movement Studies, 1986. p. 145-151,

5. Bangsbo J, laia FM, Krustrup P. The Yo-Yo intermittent recovery test: a useful tool for evaluation of physical performance in intermittent sports. Sports Med. 2008; 38 (1):37-51.

6. Boone, J. and Bourgois, J. Morphological and physiological profile of elite basketball players in Belgium. International Journal of Sports Physiology and Performance, 2013; 8(6), 630-638.

7. Coleman, A.E., Kreuzer, P., Friedrich, D.W., Juvernal, J.P., Aerobic an anaerobik responses of male colege freshmen during a season of basketball. J Sports Med, 1974; 14: 2631,

8. Csanady, M., Foster, T., Högye, M., Comparative echocarddiographic study of junior and senior basketball players. Int J Sports Med. 1986; 7: 128-132,

9. Eler S, Bereket S. Comparison of motoric and physiological parameters of elite Turk and foreing handball, Gazi University Journal of Physical Education and Sport Sciences, 2001; 6 (4): 46 - 48.

10. Erculj, F., \& Strumbelj, E. Basketball shot types and shot success in different levels of competitive basketball. PLOS ONE, 2015; 10 (6) :1-14.

11. Fan, J., Bi, S., Wang, G., Zhang, L., \& Sun, S. Sensor Fusion Basketball Shooting Posture Recognition System Based on CNN. Journal of Sensors, 2021.

12. Fox, E.L., Bowers, R.W., Foss, L.M., The physiological basis of physical education and athletics, Sounders College Publishing, p. 62-82, 675, 1988.

13. Günay, M., Tamer, K., and Cicioğlu, İ. Sports physiology and performance measurement. Ankara: Gazi Kitabevi, 2006.

14. Ji, R. Research on Basketball Shooting Action Based on Image Feature Extraction and Machine Learning. IEEE Access, 2020; $8: 138743-138751$.

15. Kasabalis A, Douda H, Tokmakidis SP. Relationship between anaerobic power and jumping of selected male volleyball players of different ages, Perceptual Motor Skills, 2005; 100 (3); 607 - 614.

16. Kılınç, F. The Effectiveness of the Training Program Prepared as a Result of the Analysis of Some Factors Affecting Performance, Kocaeli University, Institute of Health Sciences, PhD Thesis. 2003.

17. Kuter, M., Öztürk, F., Physical and physiological profile of a men's basketball team. Hacettepe University Second National Congress of Sports Sciences. Sports Sciences and Technology, Ankara, pp. 221-226, 1992.

18. Küçük, H., Doğan E., Taşmektepligil MY. The Comparision Of Selected Physiological Of Basketball Players According To Their Playing Positions, Kafkas University Journal of the Institute Social Sciences of Kafkas University Journal Of The Institute Of Social Sciences 2014; $13: 65-71$.

19. Latin, R.W.Berk, K.-Baechle, T. Physical and Performance Characteristics Of Ncaa Division I Male Basketball Players, J. Strength Cond. Res. 1994; 8:214-218.

20. Letzelter H. Kraft Training,65/83/111, Deutchland, 1986.

21. Malone, L., Gervais, P., \& Steadward, R. Shooting mechanics related to player classification and free throw success in wheelchair basketball. Journal of Rehabilitation Research and Development, 2002; 39 (6) :701-710.

22. Menevşe, A. Comparison of Anaerobic Power of Basketball Players According to the Positions They Play, Journal of Sports and Performance Research, 2013; 4 (1): 33-37.

23. Mcinnes, S.E.-Carlson, J.S.-Jones, C.J.-Mckenna M.J.,The Physiological Load Imposed On Basketball Players During Competition. J. Sports Sci. 1995; 13:387-97.

24. Narazaki, K., Berg, K., Stergiou, N., and Chen, B. Physiological demands of competitive basketball. Scandinavian Journal of Medicine \& Science in Sports, 2009; 19(3) : 425-432

25. Okazaki, V. H., Rodacki, A. L., \& Satern, M. N. A review on the basketball jump shot. Sports biomechanics, 2015; 14(2), 190-205.

26. Pamuk, O., Kaplan, T., Taşkın, H., ve Erkmen, N. Examination of some physical and physiological parameters in basketball players according to different leagues. Spormetre: Journal of Physical Education and Sport Sciences, 2008; 11(3), 141-144.

27. Paasuke M, Ereline J, nordic Gapeyeva H. Knee extension strength and vertical jumping performance in nordic combined athletes, Journal of Sports Medicine and Physical Fitness, 2001; 41; $354-361$. 
28. Pehlivan Z. Evaluation of the physical and physiological characteristics of the champions in the women's 1st away women's basketball, handball and volleyball leagues in the 1995-1996 Season, Gazi University Institute of Health Sciences, Master Thesis, Ankara, 1997.

29. Polat Ç S., Çetin E. Relation and Evaluation of Aerobic and Anaerobic Powers of Basketball Players Playing in the 2nd League with Some Motoric Parameters, Gazi Journal of Physical Education and Sport Sciences, 2018; 23 (2) : 111118.

30. Sevim Y. Training Science, Elephant Publishing House, 8. Baskı, Ankara 2010.

31. Sınırkavak, G., Dal, U., Çetinkaya, Ö. The relationship between body composition and maximal oxygen capacity in elite athletes. Journal of Cumhuriyet University Faculty of Medicine, 2004; 26 (4) : 171-176.
32. Stone, N. Physiological response to sport-specific aerobic interval training in high school male basketball players, Master Thesis,Auckland University of Technology School of Sport and Recreation, 2007. 124.

33. Tomlin, D. L. and Wenger, H. A. The relationship between aerobic fitness and recovery from high intensity intermittent exercise. Sports Medicine, 2001; 31(1), 1-11.

34. Vukasevic, V., Mitrovic, M., \& Masanovic, B. A comparative study of motor ability between elite basketball players from different regions. Sport Mont, 2020; 18(1), 3-7.

35. Young WB, James R, Montgomery I. Is muscle power related to running speed with changes of direction? The Journel of Sports Medicine and Physical Fitness. 2002; 42 (3): 282-288. 